\title{
Mathematical Modeling of Melanoma Cell Migration with an Elastic Continuum Model for the Evaluation of the Influence of Tumor Necrosis Factor-Alpha on Migration
}

\author{
Julia Vianna Gallinaro, ${ }^{1}$ Claudia Mirian de Godoy Marques, ${ }^{2}$ \\ Fernando Mendes de Azevedo, ${ }^{1}$ and Daniela Ota Hisayasu Suzuki ${ }^{1}$ \\ ${ }^{1}$ Instituto de Engenharia Biomédica, Departamento de Engenharia Elétrica, CTC, \\ Universidade Federal de Santa Catarina, 88040-900 Florianópolis, SC, Brazil \\ ${ }^{2}$ Centro de Ciências da Saúde e do Esporte, Universidade do Estado de Santa Catarina, 88080-350 Florianópolis, SC, Brazil \\ Correspondence should be addressed to Julia Vianna Gallinaro; juliavg@gmail.com
}

Received 18 April 2013; Revised 23 August 2013; Accepted 23 August 2013

Academic Editor: Hiroshi Watabe

Copyright ( 2013 Julia Vianna Gallinaro et al. This is an open access article distributed under the Creative Commons Attribution License, which permits unrestricted use, distribution, and reproduction in any medium, provided the original work is properly cited.

\begin{abstract}
An elastic continuum mathematical model was implemented to study collective C8161 melanoma cell migration during a "scratch wound" assay, in control and under the influence of the proinflammatory cytokine tumour necrosis factor-alpha (TNF- $\alpha$ ). The model has four constants: force that results from lamellipod formation $(F)$, adhesion constant between cells and extracellular matrix $(\mathrm{ECM})(b)$, cell layer elasticity modulus $(k)$, and growth rate $(\rho)$. A nonlinear regression routine was used to obtain the parameters of the model with data from an experiment made with C8161 melanoma cells, with and without TNF- $\alpha$. Coefficient of determination for both situations was $R^{2}=0.89$ and $R^{2}=0.92$, respectively. The parameters values obtained were similar to the ones found in the literature. However, the adhesion constant value decreased with the introduction of TNF- $\alpha$, which is not in accordance with expected since the presence of TNF- $\alpha$ is associated with an increased expression of integrins that would promote an enhanced adhesion among cells. The model was used in a study relating to the adhesion constant and cell migration, and the results suggested that cell migration decreases with higher adhesion, which is also not in accordance with expected. These differences would not occur if it was considered that TNF- $\alpha$ increases the elasticity modulus of the cell layer.
\end{abstract}

\section{Introduction}

Skin cancer can be divided in two groups: melanoma and nonmelanoma. Melanoma initiates with an alteration in melanocytes, skin cells that produce melanin [1]. According to the World Health Organization data, there are worldwide currently 2 to 3 million nonmelanoma cases and 132 thousand melanoma cases. Although melanoma represents around 5\% of total occurrences, it is responsible for most deaths of this type of cancer [2].

Melanoma has a radial growth phase that occurs in the epidermis. Radial growth phase cells can progress to vertical growth phase [3], in which cells grow beyond basal layer into the dermis, a vascularized region. Melanomas in radial growth phase can be surgically removed with high success rates, unlike vertical growth phase melanomas, which can become metastatic and have poor prognosis [4]. When melanoma is detected within initial stages, survival rate is of approximately $98 \%$, decreasing to $16 \%$ in melanoma advanced stages [2].

Studies have shown a relationship between inflammatory processes and the appearance and development of different types of cancer, as well as lower incidence and mortality of several types of cancer through treatment with nonsteroidal anti-inflammatory agents [5-7]. During inflammatory processes, cytokines are produced such as TNF- $\alpha$ that promotes greater activation of adhesion molecule [8]. Cancer cell migration depends on the formation of focal complexes which promote adhesion between cell and ECM $[9,10]$. Tumor cells can migrate in an individual or collective manner, 
and the way they do it is determined by their relation with the ECM. When compared to individual migration, collective migration, as in melanomas, presents higher dependence on cell-ECM adhesion [11]. In accordance with this statement, studies have shown that the presence of TNF- $\alpha$ increased melanoma cell migration [12-16].

When cutaneous melanoma is surgically removed, an inflammatory environment arises, which can favor local recurrences after surgery [15], and the exact area to be extracted during surgery is still a controversial theme. The area to be extracted is determined with classification, such as the Clark's levels, that establishes a relationship between tumor invasion level and patient's clinical prognosis, and the Breslow thickness, that refined Clark's levels by establishing a relationship between tumor thickness and patient survival prognosis [4]. According to the study developed by Kunishige et al. [17], the currently accepted extraction margin, based on a consensual opinion of 1992, is inadequate and might not be enough to completely extract cancer cells, increasing chances of recurrence, which should happen in up to $20 \%$ of cases.

Mathematical models can aid tumor growth and cell migration research since they allow simulations that are not easily obtained in in vitro or in vivo experiments. Mathematical models of tumor growth and cell migration have been developed in order to help treatment and diagnosis of several types of cancer [18-22]. Some of these models have a system of nondimensionalised equations $[18,19,22]$, which complicates quantitative comparison with experimental work. Other models, such as the one developed by Eikenberry et al. [21], have dimensionalised equations; however, they do not quantitatively compare their results with experimental work. These facts lead to models that may indicate the way cell migration and tumor invasion occur but are not necessarily capable of describing experimentally obtained situation.

Most parts of current cancer cell migration models are based on a diffusion process $[18,19,21,22]$. These studies present, generally, a principal variable: cancer cell concentration, which varies in time and space according to a diffusion equation based on Fick's law, with diffusion coefficient either constant or variable.

It is known that cell migration depends on the cell-toECM interaction through creation of adhesion complexes [9, 11]. Besides, it is also known that melanoma is a type of cancer that presents mostly collective migration [11], which implies in adherent junctions that promote cell-to-cell adhesion [23]. Diffusion processes by themselves do not account for these connections. Therefore, some models propose different manners of including parameters in the diffusion process that can represent cell-to-cell and cell-to-ECM connections, as in the model proposed by Chaplain [24].

Other models try to describe collective migration using agent-based models [25]. A study shown by Mi et al. [26] models a healing process using an elastic continuum model. This model was based on collective migration principles: during migration, cells do not separate from the edges, and no wholes are created on the cell layer. Mi et al. [26] proposed a mathematical model of enterocyte migration, during a healing process, in which cells undergo movement, deformation, and proliferation.
The aim of this work was to propose the use of a collective cell migration mathematical model that could be quantitatively compared to experimental data and allowed for an analysis on the influence of the pro-inflammatory cytokine TNF- $\alpha$ on melanoma cell migration.

\section{Methods}

2.1. Mathematical Model. The model proposed by Mi et al. [26] was a one-dimensional model that described migration of a cell layer after the opening of a wound on the layer, as in a "scratch wound" assay. The model followed some considerations: (1) it was based on a monolayer of cells, (2) there was connection between cells in the layer, (3) after the scratch (from the "scratch wound" assay), an external force was created as a result of lamellipod formation, (4) the cells in the interior of the layer did not form lamellipodia and hence were not directly actuating the motion, and (5) the cell layer came under deformation, movement, and material growth.

The variable $s$ was used to describe the position of a cell on the original cell layer and the variable $x(t, s)$ the position at time instant $t$ of the cell originally located at $s$. Variable $\widehat{s}(t, s)$ represents the hypothetical position of cell located at $s$ on the original layer at time instant $t$ if all deformation from the layer was instantaneously removed. According to balance of momentum and neglecting its acceleration term, Mi et al. [26] showed that a segment of cells, which are the offsprings of cells between $s$ and $s+d s$ of the original layer with $d s$ assumed small, would have its motion described by the following equation:

$$
\begin{aligned}
& (x(t, s+d s)-x(t, s)) \\
& \quad * b * \frac{\partial x(t, s)}{\partial t}=f(t, s+d s)-f(t, s),
\end{aligned}
$$

where $b$ is the adhesion constant between cells and the surface and $f$ the resultant force on a cross-section of the layer. In limit $d s \rightarrow 0$, (1) becomes

$$
b * \frac{\partial x}{\partial s} * \frac{\partial x}{\partial t}=\frac{\partial f}{\partial s}
$$

The strain (deformation gradient) in the cell layer can be described by the quantity

$$
\varepsilon=\frac{\partial x}{\partial \widehat{s}}-1
$$

with $\varepsilon>0$ corresponding to stretch and $-1<\varepsilon<0$ corresponding to compression.

For the constitutive relation describing the dependence of $f$ on $\varepsilon$, Mi et al. [26] used the equation

$$
f=k * \ln (\varepsilon+1)=k\left[\ln \left(\frac{\partial x}{\partial s}\right)-\ln \left(\frac{\partial \widehat{s}}{\partial s}\right)\right],
$$

where $k$ is the elasticity modulus of the cell layer.

Material growth from the layer was described using the growth gradient $g(t, s)=\partial \widehat{s} / \partial s$ on the formula

$$
g(t, s)=\exp (\rho t)
$$

where $\rho$ is the growth rate. 
From (2), (4), and (5), the following resulting equation was obtained:

$$
\frac{\partial x}{\partial s} * \frac{\partial x}{\partial t}=\frac{k}{b} * \frac{\partial}{\partial s}\left(\ln \left(\frac{\partial x}{\partial s}\right)-\rho(s) t\right) .
$$

Assuming that the location of the left boundary of the cell layer $(s=0)$ is fixed, the right boundary is free to move, and that the force applied at the right boundary is constant and equal to $F$, Mi et al. [26] proposed the use of the following initial and boundary conditions:

$$
\begin{gathered}
x(0, s)=0, \quad \text { for } 0 \leq s \leq L, \\
x(t, 0)=0, \quad \text { for } t \geq 0, \\
\frac{\partial x(t, 1)}{\partial s}=\exp \left[\left(\frac{F}{k}\right)+\rho t\right], \quad \text { for } t>0 .
\end{gathered}
$$

Considering the growth rate $\rho$ is spatially independent, (6) can be written as

$$
\frac{\partial x}{\partial t}=\frac{k}{b} * \frac{\partial^{2} x}{\partial s^{2}} *\left(\frac{\partial x}{\partial s}\right)^{-2} .
$$

From (3) and (5), the deformation gradient can be calculated with

$$
\varepsilon=\frac{\partial x}{\partial s} * \exp (-\rho t)-1
$$

2.2. Calibration. A routine nonlinear minimization of the least square error was used to estimate the parameters. The constants $k, b$, and $F$ appear on the problem only as the ratios $\kappa=k / b$ and $\varphi=F / k$. Therefore, regression was performed for the constants $\kappa, \varphi$, and $\rho$.

Experimental data used on calibration were based on the work by Redpath et al. [15]. Data were obtained from a study using C8161 human cutaneous melanoma, in control media culture and under the influence of pro-inflammatory cytokine TNF- $\alpha$. The human C8161 melanoma line was established from an abdominal wall metastasis, which indicated that it was highly invasive.

Cells were seeded in culture plates in culture medium at a concentration of $4 \times 10^{4}$ cells $/ \mathrm{mL}$ per well and were incubated for one day under standard culture conditions. On the second day, the culture medium was removed and replaced with an equal volume of fresh culture medium supplemented with TNF- $\alpha$ at a concentration of $800 \mathrm{U} / \mathrm{mL}$. On the third day, a "scratch wound" for migration assay was made in each well using a plastic pipette tip, creating a cell-free zone in each well. The reduction of distance between the scratch edges at different time points $(0,2,4,6$, and 8 hours) represented the migration of melanoma cells.

2.3. Simulation. A script was written in MATLAB to implement the model. Discretization both in time and space was obtained with the finite differences method [26]. Time and space steps were defined using the methodology proposed by Smith and Weaver [27], considering an error minor than $2 \%$ for the limits of this simulation. Time $(d t)$ and space $(d s)$ steps used were $1 / 120 \mathrm{~h}$ and $0.0125 \mu \mathrm{m}$, respectively.
TABLE 1: Parameter obtained from nonlinear regression. Values of the constants $\kappa, \varphi$, and $\rho$ obtained during model calibration, based on experimental data from Redpath et al. [15].

\begin{tabular}{lcc}
\hline Constants & Control & TNF- $\alpha$ \\
\hline$\kappa=k / b\left(\mu \mathrm{m}^{2} \mathrm{~h}^{-1}\right)$ & 104.59 & 219.92 \\
$\varphi=F / k($ dimensionless $)$ & 0.096 & 0.13 \\
$\rho\left(\mathrm{h}^{-1}\right)$ & 0.91 & 0.86 \\
\hline
\end{tabular}

\section{Results}

The curves obtained with the mathematical model for the C8161 cell migration on control and under the influence of TNF- $\alpha$ after nonlinear regression showed determination coefficient of $R^{2}=0.89$ and $R^{2}=0.92$, respectively. The values of the constants obtained are shown in Table 1.

The values of the constants shown in Table 1 were used to study the influence of proliferation and deformation on control and TNF- $\alpha$ cell migration. The results are shown in Figure 2.

Figure 3 shows the influence of the adhesion constant on migration, considering a constant elasticity modulus.

A simulation was carried out to evaluate the influence of proliferation and deformation on cell migration, by studying the deformation gradient (Figure 4). Compression was considered to be related to proliferation due to the increase on the number of cells on the layer, and extension was considered to be related to deformation due to the tension applied by the cells on the border.

\section{Discussion}

A collective cell migration model was used to simulate melanoma cell migration during a "scratch wound" assay. The model was calibrated with experimental data that was obtained from a C8161 melanoma cell line, in control and under the influence of TNF- $\alpha$.

Cell migration models based on diffusion have been used to model cancer cell migration $[18,19,21,22]$. However, the coefficient values demonstrated by some of these models, such as by Eikenberry et al. [21] and Anderson et al. [18], are small $\left(0.0009 \mathrm{~mm}^{2} \mathrm{dia}^{-1} \sim 0.07 \mathrm{~mm}^{2} \mathrm{dia}^{-1}\right)$ when compared to diffusion coefficients experimentally obtained, for instance, by Lyng et al. [28] (50 80 $\left.\mathrm{mm}^{2} \mathrm{dia}^{-1}\right)$. One possible explanation for this difference is that these models do not take the collective migration into account, as it is the case for melanoma cells. The elastic continuum model, proposed by Mi et al. [26], takes some collective migration aspects into consideration, and it is, therefore, a valid option for modeling "scratch wound" assays.

The values obtained during calibration are shown in Table 1. Since the parameters of interest $k, b$ and $F$ are presented on the model only as the ratios $\kappa=k / b$, and $\varphi=F / k$, nonlinear regression was performed for $\kappa$ and $\varphi$. However, if a reference value is set for one of the three parameters of interest, it is possible to estimate the value of the other two. Mi et al. [26] modeled enterocyte migration during wound healing and showed a value of elasticity modulus $k$ of 
approximately $44 \mathrm{nN}$. Considering melanoma cells migrating during the "scratch wound" assay demonstrate the same value of elasticity modulus, the cell layer would have, in control situation, force result from lamellipod formation $F$ of approximately $4.22 \mathrm{nN}$ and adhesion constant $b$ of approximately $0.42 \mathrm{~h} \mathrm{nN} / \mu \mathrm{m}^{2}$. Zhu et al. [12] showed that an increased integrin expression is observed in melanoma cells in the presence of TNF- $\alpha$. When relating cell migration with integrin concentration, Mi et al. [26] discussed that the elasticity modulus of cell layer should be independent of integrin concentration. Therefore, considering that melanoma cells migrating in the assay under the influence of TNF- $\alpha$ show the same elasticity modulus $k$ of the melanoma cells migrating in control situation, the cell layer would have force resulting from lamellipod formation $F$ of approximately $5.72 \mathrm{nN}$ and adhesion constant $b$ of approximately $0.2 \mathrm{~h} \mathrm{nN} / \mu \mathrm{m}^{2}$.

Based on the literature, values of protrusive force have measures that vary from $0.5 \mathrm{nN}$ to $85 \mathrm{nN}$, depending on the method used for measuring and the place of the cell where the force was measured on [29-31]. Furthermore, the increased force observed from the control to the TNF- $\alpha$ situation is also in accordance with expected. It is known that the force with which the cell propels itself depends on the connections between the cell and the surface over which it moves and these connections are made by adhesion molecules, such as integrins $[9,29]$.

The values of the adhesion constant found in both situations are of the same magnitude of the ones demonstrated by $\mathrm{Mi}$ et al. [26] (approximately $0.11 \mathrm{~h} \mathrm{nN} / \mu \mathrm{m}^{2}$ ). However, unlike what we expected, a decrease on the adhesion constant was observed with the introduction of TNF- $\alpha$. The cytokine TNF- $\alpha$ is associated with an increased expression of integrins, which enhances cell adhesion [12]. Therefore, it would be expected that the value of the adhesion constant would increase with the addition of TNF- $\alpha$, which did not happen. One hypothesis to explain this divergence would be that the elasticity modulus was not independent of the TNF- $\alpha$ concentration. It was considered that the elasticity modulus would remain the same with the introduction of TNF- $\alpha$, based on the assumptions made by Mi et al. [26] in their work. However, in case the elasticity modulus increases with TNF- $\alpha$ introduction, the adhesion constant would increase as well.

A study was performed to analyze the influence of the adhesion constant on cell migration. For this study, cell migration was simulated for different values of the constant $\kappa$. The results can be seen in Figure 3. Considering the elasticity modulus on the layer is the same for all simulations, a decrease on the constant $\kappa$ would mean an increase on the adhesion cell-to-ECM. The results show that an increase on the adhesion of the cells to ECM implies in a decrease in migration. However, Zhu et al. [12] have shown that an increase on adhesion would lead to increased migration, which is not in accordance with these results. Once again, one hypothesis to explain this divergence would be that the elasticity modulus was not independent of the TNF$\alpha$ concentration. On the other hand, these results may be in accordance with another mathematical model proposed by DiMilla et al. [32], which showed a bell-shaped curve to describe the relationship between migration speed and adhesion; that is, an increase on adhesion would lead to an increase on migration speed until a certain value, after which speed would stabilize and afterwards begin to decrease with an increase on adhesion. Thus, the values shown in Figure 3 could be located on the section of the graph in which the increase in adhesion implies decrease on migration speed.

Since the constants $k, b$, and $F$ appear in the problem only as the ratios $\kappa=k / b$, and $\varphi=F / k$, the regression for parameter estimation was performed for the constants $\kappa, \varphi$, and $\rho$. Thus, the analysis of the constants $k, b$, and $F$ requires that one of these values has to be fixed so the other two can be inferred. The previous discussion about the adhesion constant considers that the elasticity modulus is not altered when the integrin concentration increases, as suggested by $\mathrm{Mi}$ et al. [26], and this assumption can mathematically alter the results found about the adhesion constant. If the mathematical model allowed regression for the actual constants $k, b$, and $F$, this assumption would not need to be made and the role of TNF- $\alpha$ on adhesion and adhesion on migration according to the proposed model could be more precisely discussed.

Considering, for example, that the elasticity modulus would change with the introduction of TNF- $\alpha$, there is the possibility that the adhesion constant would increase with the TNF- $\alpha$, as expected. If the elasticity modulus increases with TNF- $\alpha$, by a factor of at least 2.1 , the adhesion constant would increase as well. In Figure 5, one can see the values of adhesion constant for different values of elasticity modulus, considering their ratio $\kappa=219.92 \mu \mathrm{m}^{2} \mathrm{~h}^{-1}$ obtained with the nonlinear regression and shown in Table 1 , for TNF- $\alpha$. For values of elasticity modulus $k$ greater than $92.37 \mathrm{nN}$, the adhesion constant $b$ has values greater than the control situation, $0.42 \mathrm{~h} \mathrm{nN} \mu \mathrm{m}^{-2}$. The adhesion constant is, on this model, related to the adhesion between the cells and the surface. It does not consider, however, the adhesion between cells observed on collective cell migration [23]. The elasticity modulus, on the other hand, could be related to the adhesion between cells on the layer, since it relates the force that is being applied and the deformation on the layer, as it is established on (4). If the TNF- $\alpha$ affects the adhesion between cells, as well as the adhesion between the cells and the surface, this could mean that the elasticity modulus would change with TNF- $\alpha$, when compared to the control situation.

Table 1 shows there was a reduction in the growth rate when TNF- $\alpha$ was introduced. The role of TNF- $\alpha$ on cancer cell proliferation is still paradoxal [33]. In the present work, proliferation rate of melanoma cells decreased with the introduction of TNF- $\alpha$. Kuninaka et al. [34] showed that TNF- $\alpha$ inhibited the growth of tumor cells and Marques [8] observed a reduction in C8161 cell viability in TNF- $\alpha$ treated cells. In this proposed model, the proliferation rate accounts for both increase and decrease in the population cell number. Therefore, the results are in accordance with the results shown by Kuninaka et al. [34] and Marques [8], since both growth inhibition and cell viability reduction would lead to a decrease on the proliferation rate. Even though proliferation observed on the cells treated with TNF$\alpha$ was smaller than the proliferation observed on the control 


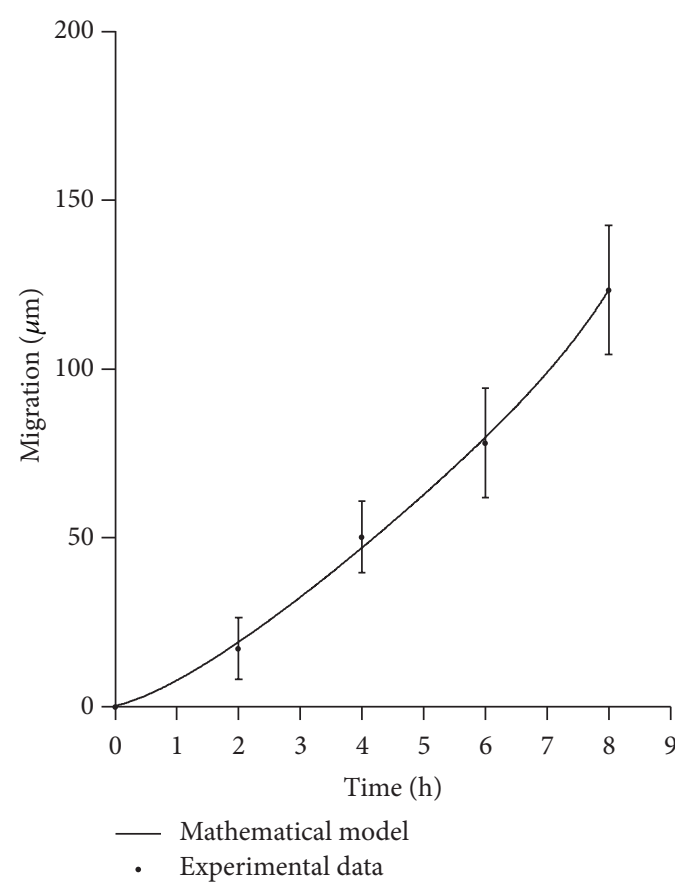

(a)

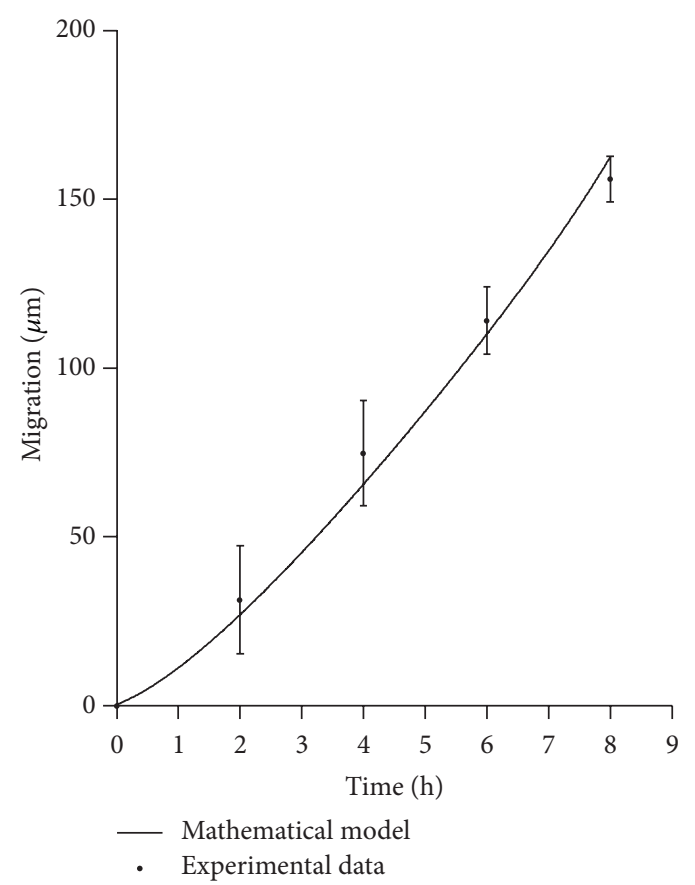

(b)

FIGURE 1: Mathematical model and experimental data after nonlinear regression. Curve obtained with the simulation of the mathematical model after nonlinear regression using experimental data from C8161 cell line on control situation (a), with $R^{2}=0.89$, and with TNF- $\alpha$ (b), with $R^{2}=0.92$. Experimental data are represented as mean \pm standard deviation, $n=7$.

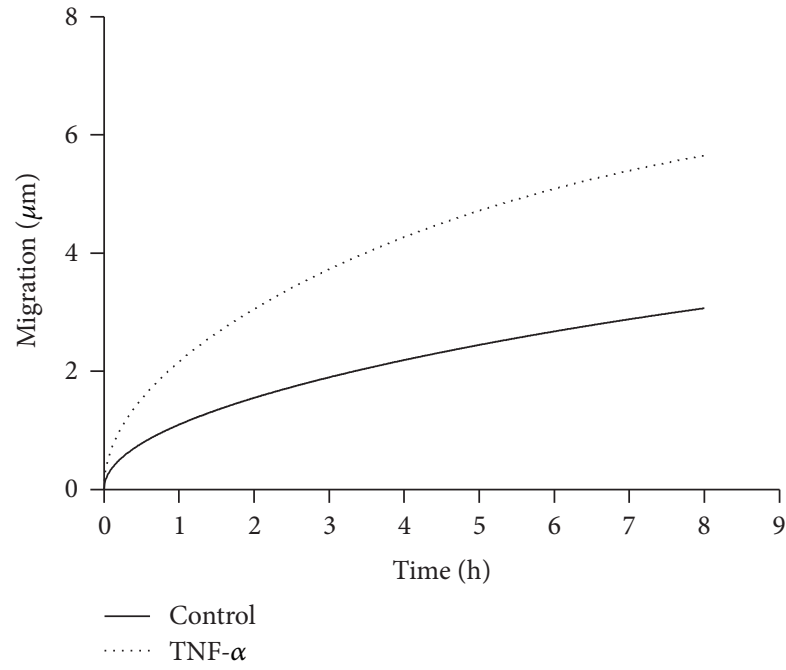

Figure 2: Migration due to deformation. Simulation of the model obtained for the hypothetical situation in which migration would occur exclusively due to deformation. The values of $\kappa$ and $\varphi$ used are the ones from Table 1. $\rho=0 \mathrm{~h}^{-1}$ for both situations: control and TNF- $\alpha$.

situation, the final migration was greater for these cells due to the greater deformation observed in Figure 2.

As observed in Figure 4, migration is, at the beginning, more dependent on deformation, becoming more dependent

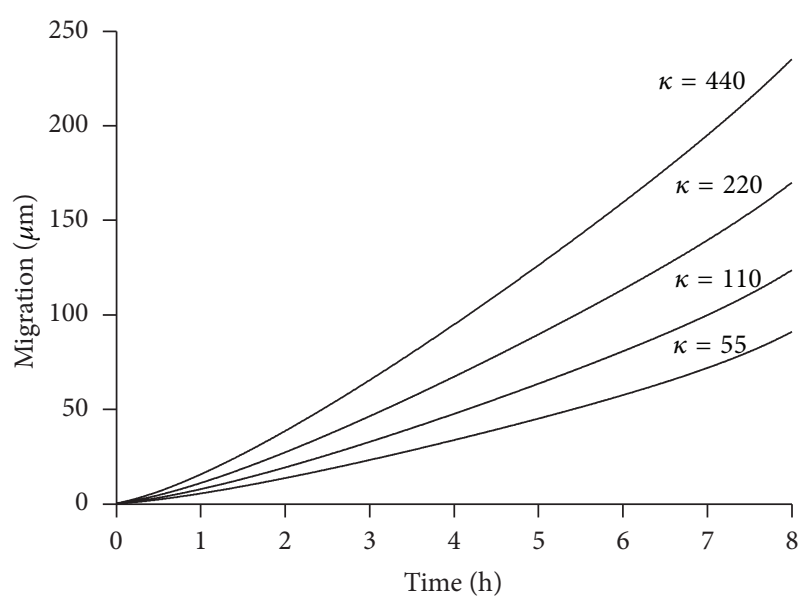

Figure 3: Influence of the adhesion constant on cell migration. Cell migration for different values of $\kappa \cdot \varphi=0.1$ and $\rho=0.9 \mathrm{~h}^{-1}$. Considering a constant elasticity modulus, cell migration decreases with an increase on adhesion. All values of $\kappa$ are expressed in $\mu \mathrm{m}^{2} \mathrm{~h}^{-1}$.

on proliferation after a while. At the same time, constant proliferation rate gives the migration an exponential characteristic. On "scratch wound" assays of cell migration, this is not always the case. In some of these assays, the migration curve has a saturation shape $[8,35,36]$, which is not in accordance with the exponential shape observed in Figure 1. Studies suggest that the proliferation rate in "scratch wound" 

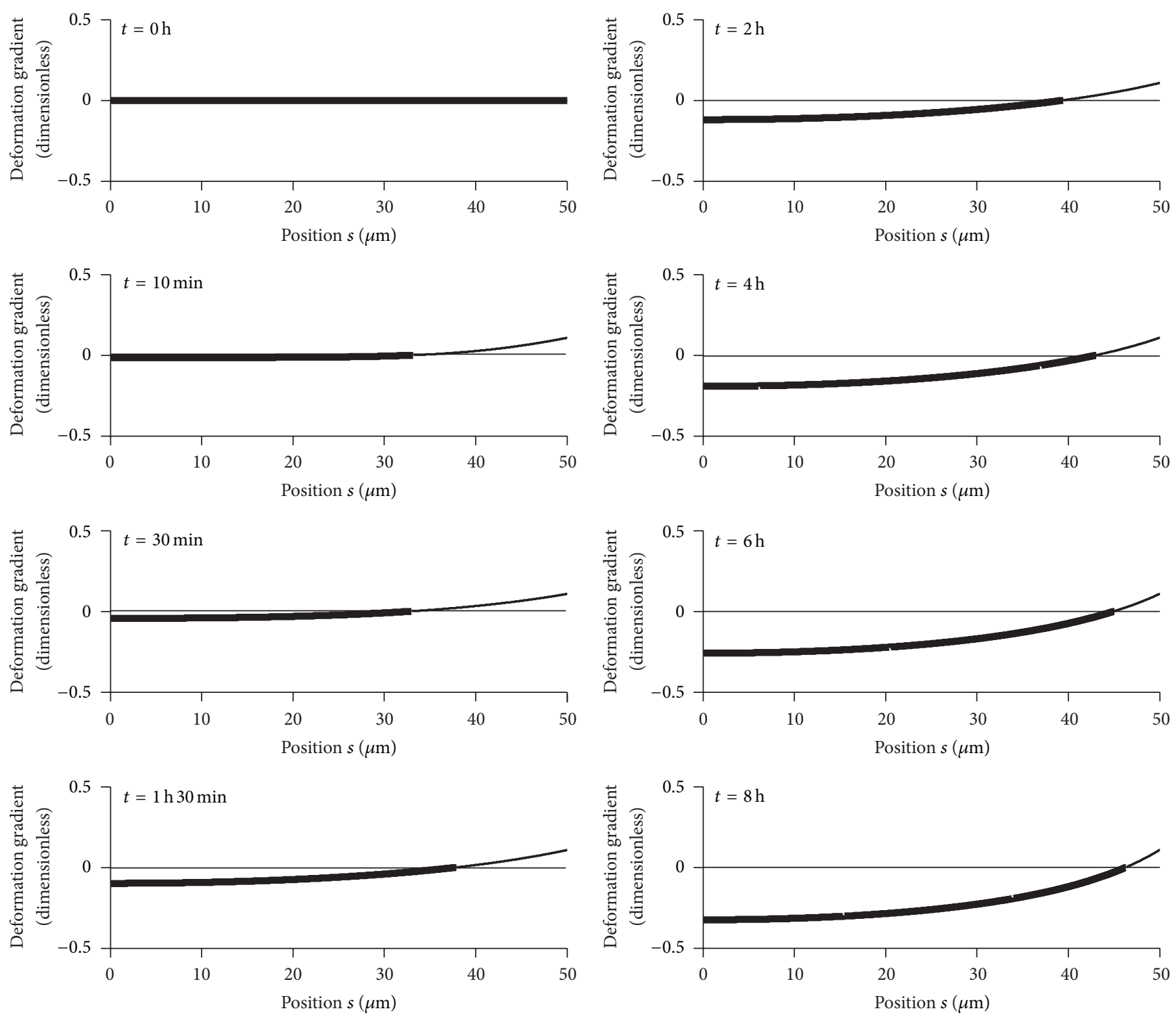

Figure 4: Deformation gradient of cell as a function of their position on the original layer in different time instants. Thick and thin lines indicate cells in compression and extension, respectively, except on $t=0 \mathrm{~h}$, when the cells are in rest. On the beginning (left column), movement is dominated by deformation, causing extension on the cells near the border. After some time (right column), movement is dominated by proliferation, increasing compression on the layer as a whole. For this simulation, $\varphi=0.1, \kappa=440 \mu \mathrm{m}^{2} \mathrm{~h}^{-1}$, and $\rho=0.1 \mathrm{~h}^{-1}$.

assays can vary, depending on time and on the location on the cell layer [26]. More studies could be made to determine if the constant proliferation rate is indeed to be adequate for this kind of assay. A nonconstant proliferation rate could also alter the adhesion constant values, with and without TNF$\alpha$, found with regression. This could be another hypothesis for the differences between model and experimental results discussed previously.

Although the numerical method used to solve the model is the one proposed by $\mathrm{Mi}$ et al. [26] and the results are mostly in accordance with experimental values found in the literature, as discussed previously, it is important to analyze the influence of discretization on the obtained results. The analysis was performed according to the methodology proposed by Smith and Weaver [27], and, for the limits of this simulation, the greater error found was of less than $2 \%$ on the migration curve.

\section{Conclusion}

A collective cell migration model was used to simulate melanoma cell migration in a "scratch wound" assay. The model takes into consideration aspects of collective cell migration, such as the adhesion between cells on the cell layer, which is not the case for the most part of current tumor growth models, based on simple diffusion process. With some exceptions, great part of tumor growth models is nondimensionalised, which does not allow quantitative analysis. In this work, a dimensionalised model was implemented and calibrated based on the experimental data, resulting in parameters that 


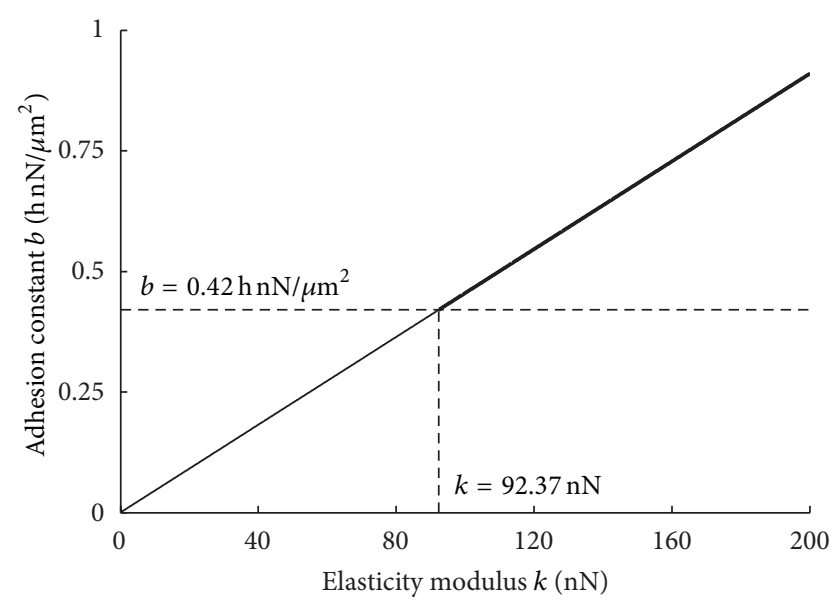

Figure 5: Adhesion constant for different values of elasticity modulus, considering their ratio $\kappa=219.92 \mu \mathrm{m}^{2} \mathrm{~h}^{-1}$ obtained with the nonlinear regression and showed in Table 1 , for TNF- $\alpha$. The thick line shows values of adhesion constant that are greater than the value

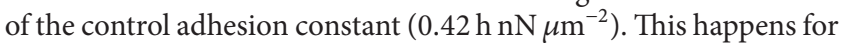
values of elasticity modulus greater than $92.37 \mathrm{nN}$.

have values comparable to experimental work, in most cases. The main differences found, involving the adhesion constant and migration with the introduction of TNF- $\alpha$, could be related to the mathematical model itself or the proliferation rate used. These differences would not happen in case the TNF- $\alpha$ would affect and increase the elasticity modulus of the layer. Further analysis on the proliferation rate and a model that allowed for regression directly of the adhesion constant and the elasticity modulus could provide more insights on the differences found.

\section{Acknowledgment}

The authors thank CNPq (National Counsel of Technological and Scientific Development, Brazil) for the financial support.

\section{References}

[1] American Cancer Society, "Melanoma Skin Cancer Overview," 2011, http://www.cancer.org/Cancer/SkinCancer-Melanoma/index.

[2] American Cancer Society, "Cancer Facts \& Figures," 2011, http://www.cancer.org/Research/CancerFactsFigures/CancerFactsFigures/cancer-facts-figures-2011.

[3] V. Gray-Schopfer, C. Wellbrock, and R. Marais, "Melanoma biology and new targeted therapy," Nature, vol. 445, no. 7130, pp. 851-857, 2007.

[4] A. Breslow, "Thickness, cross-sectional areas and depth of invasion in the prognosis of cutaneous melanoma," Annals of Surgery, vol. 172, no. 5, pp. 902-908, 1970.

[5] A. Mantovani, P. Allavena, A. Sica, and F. Balkwill, "Cancerrelated inflammation," Nature, vol. 454, no. 7203, pp. 436-444, 2008 .
[6] S. Ben-Eliyahu, "The promotion of tumor metastasis by surgery and stress: immunological basis and implications for psychoneuroimmunology," Brain, Behavior, and Immunity, vol. 17, supplement 1, pp. S27-S36, 2003.

[7] F. Balkwill and L. M. Coussens, "Cancer: an inflammatory link," Nature, vol. 431, no. 7007, pp. 405-406, 2004.

[8] C. M. G. Marques, Tissue Engineered Human Skin Models to Study the Effect of Inflammation on Melanoma Invasion, University of Sheffield, Sheffield, UK, 2010.

[9] D. A. Lauffenburger and A. F. Horwitz, "Cell migration: a physically integrated molecular process," Cell, vol. 84, no. 3, pp. 359369, 1996.

[10] A. J. Ridley, M. A. Schwartz, K. Burridge et al., "Cell migration: integrating signals from front to back," Science, vol. 302, no. 5651, pp. 1704-1709, 2003.

[11] P. Friedl and K. Wolf, "Tumour-cell invasion and migration: diversity and escape mechanisms," Nature Reviews Cancer, vol. 3, no. 5, pp. 362-374, 2003.

[12] N. Zhu, P. C. Eves, E. Katerinaki et al., "Melanoma cell attachment, invasion, and integrin expression is upregulated by tumor necrosis factor $\alpha$ and suppressed by $\alpha$ melanocyte stimulating hormone," Journal of Investigative Dermatology, vol. 119, no. 5, pp. 1165-1171, 2002.

[13] N. Zhu, R. Lalla, P. Eves et al., "Melanoma cell migration is upregulated by tumour necrosis factor- $\alpha$ and suppressed by $\alpha$-melanocyte-stimulating hormone," British Journal of Cancer, vol. 90, no. 7, pp. 1457-1463, 2004.

[14] E. Katerinaki, J. W. Haycock, R. Lalla et al., "Sodium salicylate inhibits TNF- $\alpha$-induced NF- $\kappa$ B activation, cell migration, invasion and ICAM-1 expression in human melanoma cells," Melanoma Research, vol. 16, no. 1, pp. 11-22, 2006.

[15] M. Redpath, C. M. G. Marques, C. Dibden, A. Waddon, R. Lalla, and S. MacNeil, "Ibuprofen and hydrogel-released ibuprofen in the reduction of inflammation-induced migration in melanoma cells," British Journal of Dermatology, vol. 161, no. 1, pp. 25-33, 2009.

[16] I. Cantón, P. C. Eves, M. Szabo et al., "Tumor necrosis factor $\alpha$ increases and $\alpha$-melanocyte-stimulating hormone reduces uveal melanoma invasion through fibronectin," Journal of Investigative Dermatology, vol. 121, no. 3, pp. 557-563, 2003.

[17] J. H. Kunishige, D. G. Brodland, and J. A. Zitelli, "Surgical margins for melanoma in situ," Journal of the American Academy of Dermatology, vol. 66, no. 3, pp. 438-444, 2012.

[18] A. Anderson, M. Chaplain, E. Newman, R. Steele, and A. Thompson, "Mathematical modelling of tumour invasion and metastasis," Journal of Theoretical Medicine, vol. 2, no. 2, pp. 129151, 2000.

[19] A. R. A. Anderson, "A hybrid mathematical model of solid tumour invasion: the importance of cell adhesion," Mathematical Medicine and Biology, vol. 22, no. 2, pp. 163-186, 2005.

[20] P. Ciarletta, L. Foret, and M. B. Amar, "The radial growth phase of malignant melanoma: multi-phase modelling, numerical simulations and linear stability analysis," Journal of the Royal Society Interface, vol. 8, no. 56, pp. 345-368, 2011.

[21] S. Eikenberry, C. Thalhauser, and Y. Kuang, "Tumor-immune interaction, surgical treatment, and cancer recurrence in a mathematical model of melanoma," PLoS Computational Biology, vol. 5, no. 4, Article ID e1000362, 2009.

[22] S. Tohya, A. Mochizuki, S. Imayama, and Y. Iwasa, "On rugged shape of skin tumor (basal cell carcinoma)," Journal of Theoretical Biology, vol. 194, no. 1, pp. 65-78, 1998. 
[23] P. Friedl and D. Gilmour, "Collective cell migration in morphogenesis, regeneration and cancer," Nature Reviews Molecular Cell Biology, vol. 10, no. 7, pp. 445-457, 2009.

[24] M. A. J. Chaplain, "Multiscale mathematical modelling in biology and medicine," IMA Journal of Applied Mathematics, vol. 76, no. 3, pp. 371-388, 2011.

[25] M. L. Wynn, P. M. Kulesa, and S. Schnell, "Computational modelling of cell chain migration reveals mechanisms that sustain follow-the-leader behaviour," Journal of the Royal Society, Interface, vol. 9, no. 72, pp. 1576-1588, 2012.

[26] Q. Mi, D. Swigon, B. Rivière, S. Cetin, Y. Vodovotz, and D. J. Hackamz, "One-dimensional elastic continuum model of enterocyte layer migration," Biophysical Journal, vol. 93, no. 11, pp. 3745-3752, 2007.

[27] K. C. Smith and J. C. Weaver, "Electrodiffusion of molecules in aqueous media: a robust, discretized description for electroporation and other transport phenomena," IEEE Transactions on Bio-Medical Engineering, vol. 59, no. 6, pp. 1514-1522, 2012.

[28] H. Lyng, O. Haraldseth, and E. K. Rofstad, "Measurement of cell density and necrotic fraction in human melanoma xenografts by diffusion weighted magnetic resonance imaging," Magnetic Resonance in Medicine, vol. 43, no. 6, pp. 828-836, 2000.

[29] R. Ananthakrishnan and A. Ehrlicher, "The forces behind cell movement," International Journal of Biological Sciences, vol. 3, no. 5, pp. 303-317, 2007.

[30] C. A. Brunner, A. Ehrlicher, B. Kohlstrunk, D. Knebel, J. A. Käs, and M. Goegler, "Cell migration through small gaps," European Biophysics Journal, vol. 35, no. 8, pp. 713-719, 2006.

[31] M. Prass, K. Jacobson, A. Mogilner, and M. Radmacher, "Direct measurement of the lamellipodial protrusive force in a migrating cell," Journal of Cell Biology, vol. 174, no. 6, pp. 767-772, 2006.

[32] P. A. DiMilla, K. Barbee, and D. A. Lauffenburger, "Mathematical model for the effects of adhesion and mechanics on cell migration speed," Biophysical Journal, vol. 60, no. 1, pp. 15-37, 1991.

[33] G. M. Anderson, M. T. Nakada, and M. DeWitte, "Tumor necrosis factor- $\alpha$ in the pathogenesis and treatment of cancer," Current Opinion in Pharmacology, vol. 4, no. 4, pp. 314-320, 2004.

[34] S. Kuninaka, T. Yano, H. Yokoyama et al., "Direct influences of pro-inflammatory cytokines (IL- $1 \beta$, TNF- $\alpha$, IL- 6 ) on the proliferation and cell-surface antigen expression of cancer cells," Cytokine, vol. 12, no. 1, pp. 8-11, 2000.

[35] A. B. Beshir, G. Ren, A. N. Magpusao, L. M. Barone, K. C. Yeung, and G. Fenteany, "Raf kinase inhibitor protein suppresses nuclear factor- $\kappa \mathrm{B}$-dependent cancer cell invasion through negative regulation of matrix metalloproteinase expression," Cancer Letters, vol. 299, no. 2, pp. 137-149, 2010.

[36] O. Debeir, V. Mégalizzi, N. Warzée, R. Kiss, and C. Decaestecker, "Videomicroscopic extraction of specific information on cell proliferation and migration in vitro," Experimental Cell Research, vol. 314, no. 16, pp. 2985-2998, 2008. 


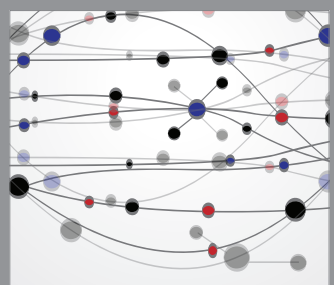

The Scientific World Journal
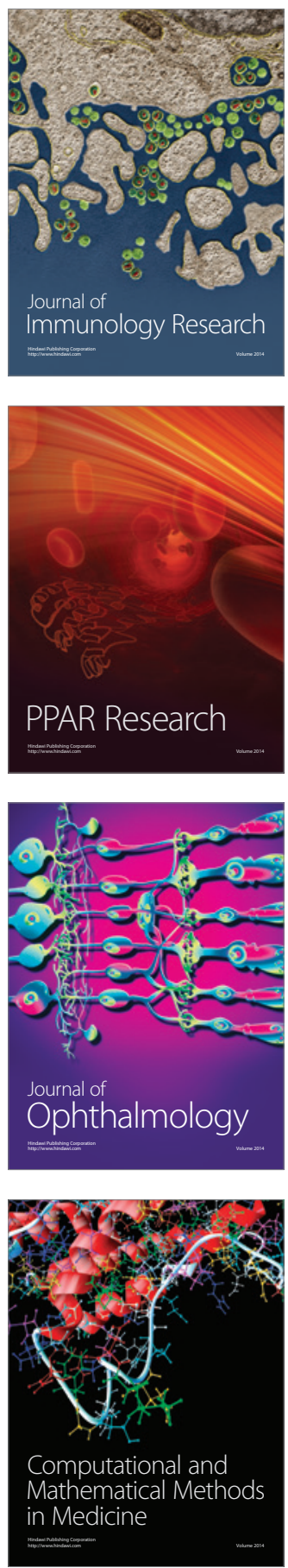

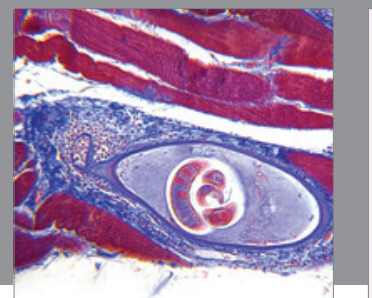

Gastroenterology

Research and Practice
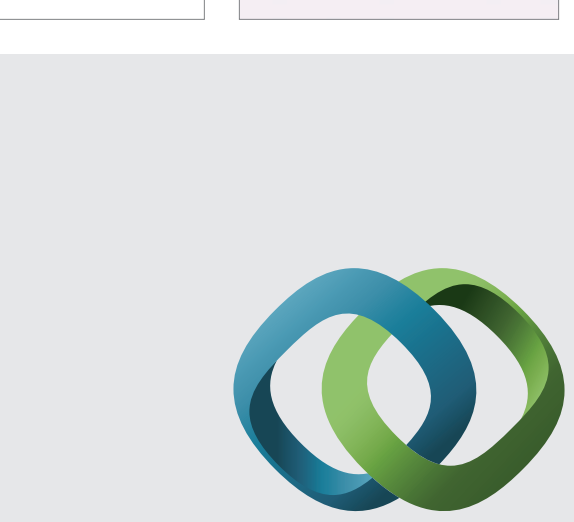

\section{Hindawi}

Submit your manuscripts at

http://www.hindawi.com
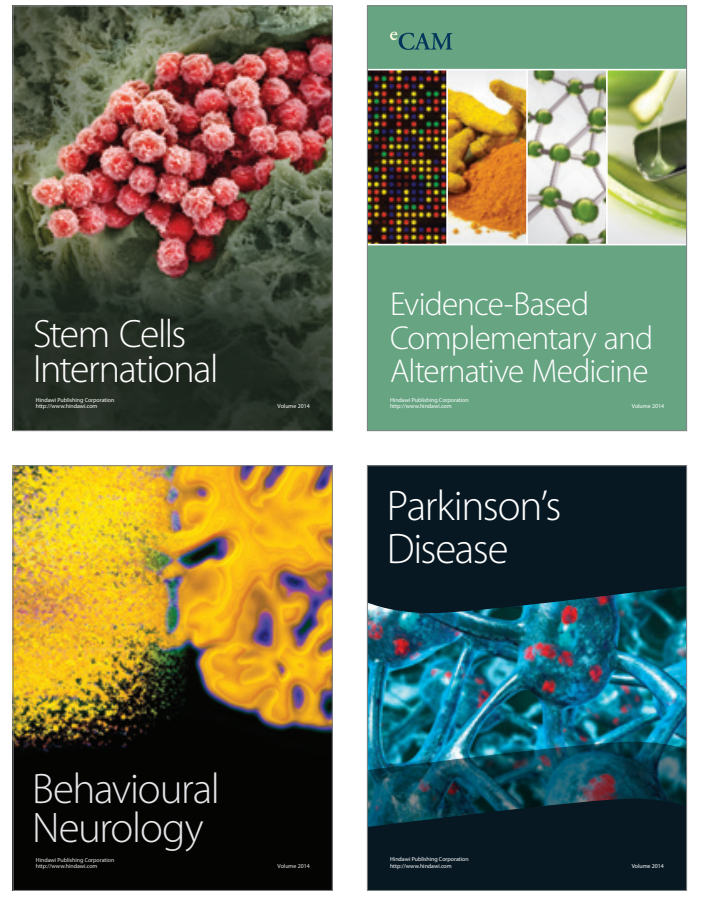
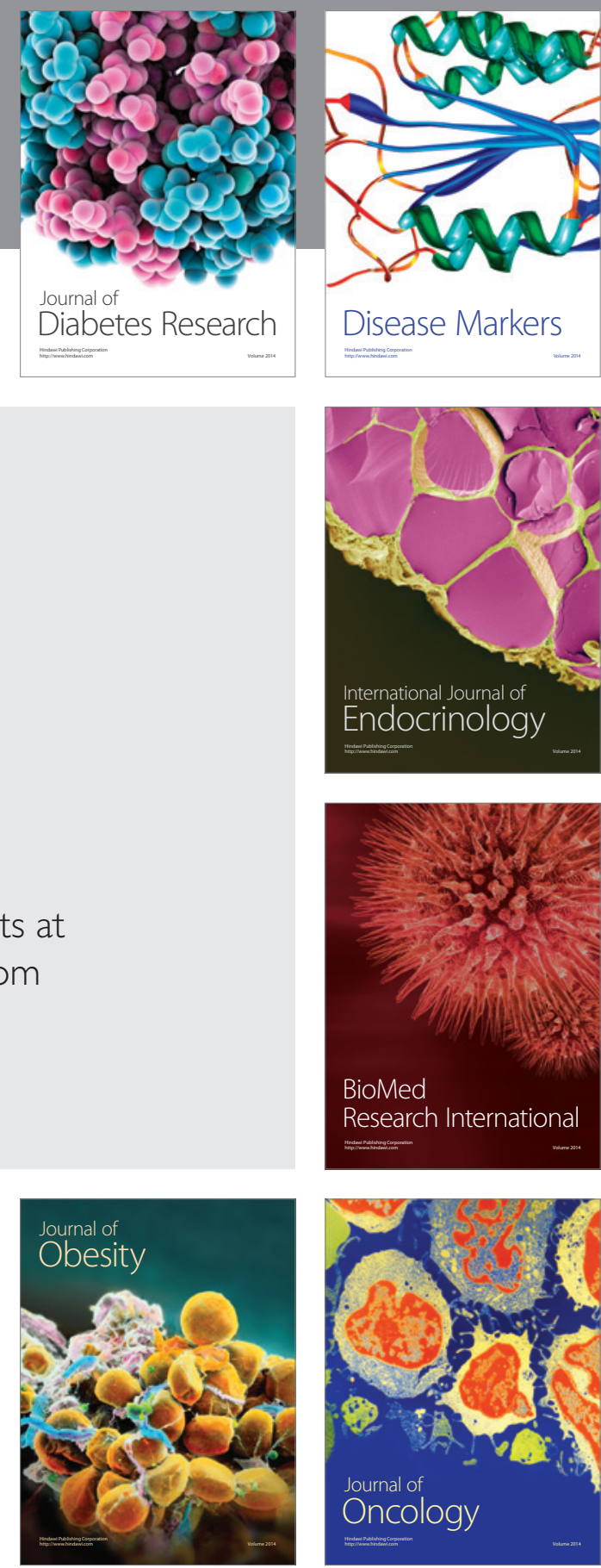

Disease Markers
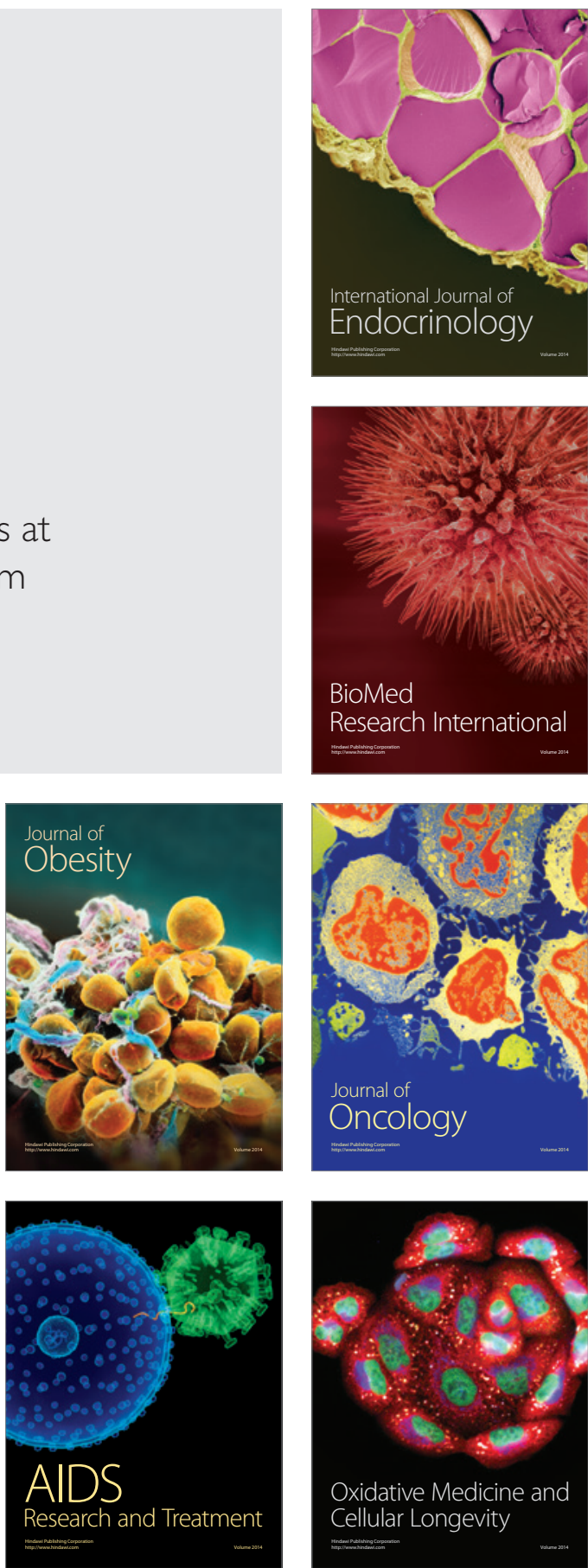